\title{
Thermodynamic Analysis of Vapour Absorption Refrigeration Cycle Using Different Working Fluids
}

\author{
*A. SAThiamourtty ${ }^{1}$, K. ASHOK ${ }^{2}$ \& B. PAVANAN ${ }^{3}$ \\ ${ }^{1}$ Department of Mechanical Engineering, Pondicherry Engineering College, Pondicherry, India. \\ ${ }^{2}$ Department of Mechanical Engineering, Pondicherry Engineering College, Pondicherry, India. \\ ${ }^{3}$ Department of Mechanical Engineering, RGCET, Pondicherry, India.
}

\begin{abstract}
All industrial process uses a lot of thermal energy by burning fossil fuel to produce steam or heat for the purpose. After the processes, heat is rejected to the surrounding as waste. This waste heat can be converted to useful refrigeration by using a heat operated refrigeration system, such as vapour absorption refrigeration system In this work, a thermodynamic analysis of ammonia lithium-nitrate water solution and ammonia water sodium hydroxide solution absorption refrigeration cycle has been studied at low generator temperature heat source 60 to $80^{\circ} \mathrm{C}$ and the range of evaporator temperature -4 to $0^{\circ} \mathrm{C}$. The influences of operating temperature on the thermal load of components, coefficient of performance are investigated. The COP of the absorption system increases with increase in evaporator temperature and generator temperature.
\end{abstract}

Keywords: Vapour absorption, heat operated, generator, evaporator, absorber

\section{INTRODUCTION}

Most of industrial processes use thermal energy by burning fossil fuel to produce steam or heat for the purpose. After any of these processes, heat is rejected to the surrounding as waste. This waste heat can be utilized for cooling by using a heat operated refrigeration system, such as an absorption refrigeration cycle. Thus, electricity purchased from utility companies for conventional vapour compression refrigerators can be reduced. The use of heat operated refrigeration systems helps to reduce problems related to environmental issues such as the so called greenhouse effect from $\mathrm{CO}_{2}$ emission from the combustion of fossil fuels in utility power plants.

Another difference between absorption systems and conventional vapour compression systems is the working fluid used. Most vapour compression systems commonly use chlorofluorocarbon refrigerants (CFCs), because of their favourable thermo physical properties. It is through the restricted use of CFCs, due to depletion of the ozone layer that will make absorption systems more prominent. However, although absorption systems seem to provide many advantages, vapour compression systems still dominate all market sectors. In order to promote the use of absorption systems, further development is required to improve their performance and reduce cost.

The early development of an absorption cycle dates back to the 1700's. It was known that ice could be produced by an evaporation of pure water from a vessel contained within an evacuated container in the presence of sulphuric acid. In 1810 , ice could be made from water in a vessel, which was connected to another vessel containing sulphuric acid. As the acid absorbed water vapour, causing a reduction of temperature, layers of ice were formed on the water surface. The major problems of this system were corrosion and leakage of air into the vacuum vessel. In 1859, Ferdinand introduced a novel machine using water/ammonia as the working fluid. This machine took out a US patent in 1860 . Machines based on this patent were used to make ice and store food. It was used as a basic design in the early age of refrigeration development.

In the 1950's, a system using lithium bromide/water as the working fluid was introduced for industrial applications. A few years later, a double-effect absorption system was introduced and has been used as an industrial standard for a high performance heat-operated refrigeration cycle. The aim of this paper is to provide basic background and review existing literatures on absorption refrigeration technologies. A number of absorption refrigeration systems and research options are provided and discussed. It is hoped that, this paper should be useful for any newcomer in this field of refrigeration technology.

\section{COMPARISON OF VAPOUR COMPRESSION AND ABSORPTION SYSTEM}

Absorption refrigeration system is a system that uses a heat source (e.g., solar energy, a fossil-fuelled flame, waste heat from factories, or district heating systems) which provides the energy needed to drive the cooling process. This system operates based on absorption process rather than compression process.

Similar to vapour compression system, the cooling effect is produced through evaporation process of the refrigerant in the evaporator and the heat absorbed in the evaporator is released to the atmosphere via the condenser. The vapour absorption refrigeration system also comprises of all the processes taking 
place in vapour compression refrigeration system such as condensation, expansion, evaporation, and compression.

Although both absorption system and compression system have similarities in producing cooling effect in the evaporator, they have some differences. The differences of absorption system and compression system can be schematically compared in Figure. As it can be seen in Figure, one of the major differences between mechanical vapour compression system and absorption system is the method of transferring the refrigerant from the lower pressure system to the higher pressure system. In the vapour compression system, the refrigerant is transferred from the lower pressure system to the higher pressure systems by mechanical compressor. The mechanical compressor sucks the refrigerant vapour and compresses it to the high pressure. In addition, the mechanical compressor also creates the refrigerant flow in the whole compression cycle. In the absorption system, the refrigerant is transferred from the lower pressure system to the higher pressure systems through a mechanism of absorption and desorption process carried out by two different devices called as absorber and generator (desorber), respectively, together with solution pump, solution valve, and solution heat exchanger. Therefore the compressor in the vapour compression system is replaced by the absorber and generator loop or it can be called as "chemical compressor". In addition, the refrigerant flow in the whole absorption cycle is created by absorption process of the refrigerant in the absorber by the solution called absorbent and transported to the generator using solution pump. The absorption process at the absorber and desorption process at the generator make it possible to use a solution pump with low power input to increase the pressure between the condenser and the evaporator.

The presence of the absorption and desorption devices replacing the mechanical compressor has a consequence in the increase the overall system volume. However the displacement volume and power consumption for compression of the liquid in absorption refrigeration system are much smaller as compared with vapour compression systems.

Another major difference between the vapour compression and vapour absorption cycle is the method in which the energy input is given to the system. In vapour compression systems, the energy input needed to operate the cycle is provided in the form of mechanical work to drive the compressor. This mechanical work input usually comes from the electric motor run by the electricity. In the absorption systems, the energy input needed to operate the cycle is provided in the form of the heat to separate the refrigerant from the solution in the generator. This heat source can be supplied from renewable energy such as solar, geothermal energy, and biomass or waste heat sources such as exhausts on diesel engines and industrial plants. The heat can also be created by other sources like natural gas, kerosene, heater, etc. though these sources are usually used only in the small systems. As the absorption refrigeration systems are operated using heat source and the only component of this system with moving mechanical parts is the liquid pump, these systems has very lower vibration and thus lower noise with no lubrication needed than those of mechanical compression systems.

Another difference between the vapour compression and vapour absorption cycle is the working fluid used. In vapour compression systems, the working fluid used is only refrigerant fluid. Most vapour compression systems commonly use chlorofluorocarbon refrigerants (CFCs) because of their excellent thermos physical properties. It is through the restricted use of CFCs, due to depletion of the ozone layer that will make absorption systems more prominent. In absorption refrigeration system, the working fluid used is usually a pair of absorbent and refrigerant fluid. The two most common working fluids in absorption refrigeration cycle are water/LiBr and ammonia/water. In water/LiBr working fluid, water works as refrigerant and aqueous $\mathrm{LiBr}$ solution works as absorbent and in ammonia/water system ammonia works as refrigerant and water works as absorbent.

\section{PRINCIPLE OF ABSORPTION REFRIGERATION PROCESS}

Absorption refrigeration system basically consists of four main components, namely absorber, generator, condenser, and evaporator. In addition, it requires working fluid which consists of refrigerant and absorbent. Other supporting components necessary for the basic absorption refrigeration cycle are solution pump, pressure reduction valve, expansion valve, solution heat exchanger (SHX) and refrigerant heat exchanger (RHX). In this system, the refrigerant undergoes a phase change in the condenser and evaporator, and the absorbent solution undergoes a concentration change in the absorber and the generator.

The basic absorption refrigeration process can be schematically drawn in diagram as shown in Figure. The solution leaving from absorber (stream7) is moved to the higher pressure system by solution pump, creating high pressure cold stream (stream 8). Ideally the solution leaving the absorber is in saturation condition taking into account the absorber pressure (lower pressure) and temperature. This solution is rich in refrigerant fluid therefore it can be named as rich solution.

The high pressure cold stream is then preheated in the solution heat exchanger using the heat transferred from the solution leaving the generator. The rich solution leaving the solution heat exchanger (stream 9) then enters the generator. In the generator, vaporization process takes place creating refrigerant vapour and poor solution. The desorption process between the absorbent and refrigerant is usually endothermic process, therefore to undergo this process the heat needs to be supplied from the external source such as solar, geothermal energy, and biomass or waste heat sources such as exhausts on diesel engines and industrial plants. 
The refrigerant vapour leaving the generator (stream 1) comes to the refrigerant loop and enters the condenser. In the condenser, condensation process takes place and all refrigerant is condensed into saturated liquid corresponds to the condenser pressure (higher pressure) and temperature. The heat released from this condensation process is discharged to the atmosphere through a cooling system at ambient temperature.

The saturated liquid refrigerant leaving from the condenser (stream 2) moves to the evaporator through refrigerant valve to reduce its pressure to the evaporator pressure (low pressure). This expansion process in the refrigerant valve is an isenthalpic expansion. The refrigerant leaving the refrigerant valve (stream 4) enters the evaporator and the evaporation process takes place.

As the saturation temperature of the refrigerant at lower pressure is much lower than room temperature, the heat from desired cooling chamber is absorbed to the evaporator creating the evaporation process to the refrigerant, and therefore gives cooling effect to the cooling/refrigeration chamber.

Back to the solution loop in the generator, the solution leaving the generator (stream 10) has low concentration in refrigerant and thus it is called as poor solution. As the stream leaving from the generator has high temperature, it can be useful to utilize the heat of this stream to pre-heat the rich solution before entering the generator. The heat from the solution leaving the generator is transferred to the rich solution entering the generator by means of solution heat exchanger (SHX).

The poor solution leaving the solution heat exchanger moves to the absorber through solution valve to reduce its pressure to the lower pressure. Similar with the expansion process in the refrigerant valve, the expansion process in the pressure reduction valve is also an isenthalpic expansion. The poor solution leaving the solution valve (stream 12) enters the absorber to undergo the absorption process.

The poor solution enters the absorber is in sub-cooled condition corresponds to its temperature and absorber pressure. Therefore, when the vapour refrigerant (stream 6) enters the absorber, the refrigerant vapour is absorbed by the solution. As the absorption process takes place, the mixing process also takes place. The mixing process between absorbent and refrigerant is usually exothermic process, and therefore during the absorption process the heat is released from the solution and the solution temperature increases. To maintain the absorption process remains take place at desired temperature.(absorber temperature), the heat of absorption needs to be dissipated to the ambient. This heat is dissipated to the ambient by means of cooling system at ambient temperature. Once the solution reach its saturation condition corresponds to absorber pressure and temperature, the solution is unable to absorb more vapour refrigerant. This solution then leaves the absorber to the generator and the solution loop is completed.
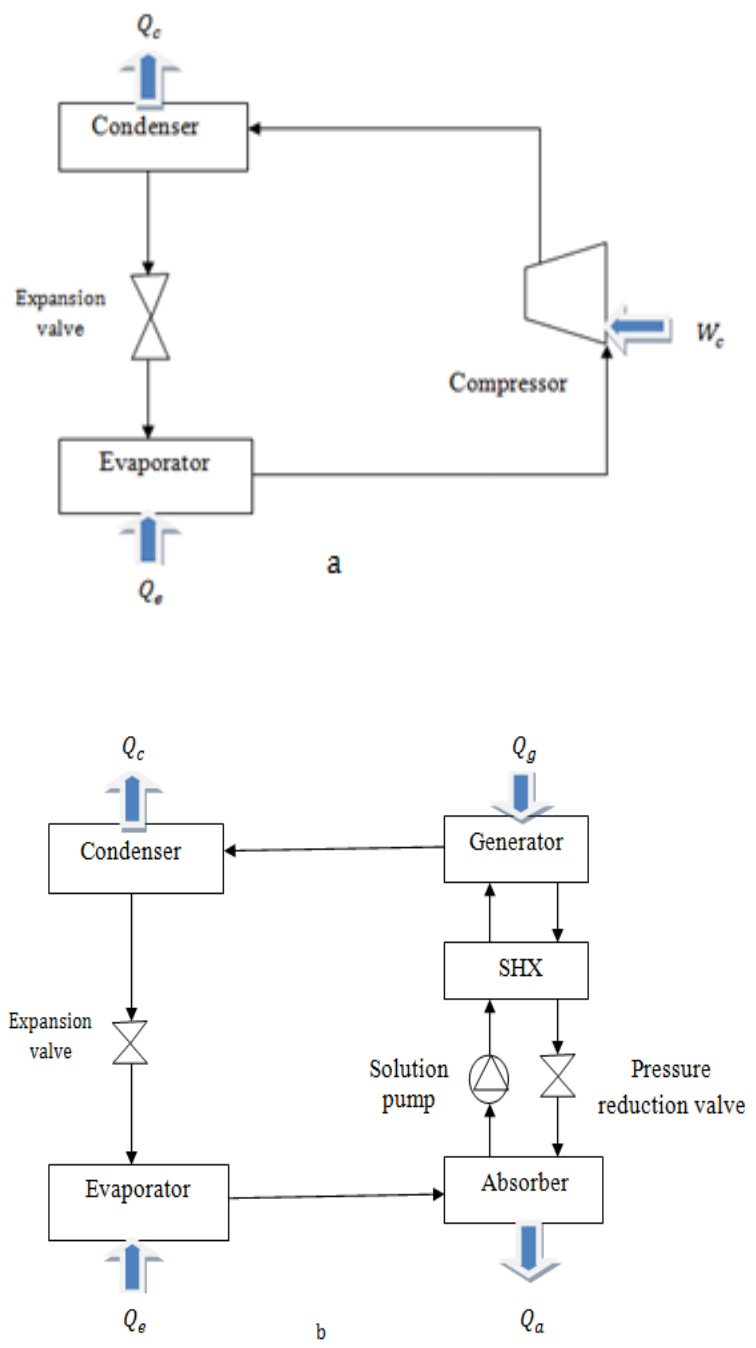

Fig. Schematic diagram of (a) Mechanical vapour compression system and (b) Vapour Absorption system

\section{THEORETICAL ANALYSIS}

Refrigerant and absorbent pair

Pair 1

$\begin{array}{ll}\text { Refrigerant } & \text { - Ammonia } \\ \text { Absorbent } & \text { - lithium nitrate and water }\end{array}$

By adding water to the ammonia lithium nitrate solution improves the solubility of the solution.

Pair 2

$\begin{array}{ll}\text { Refrigerant } & \text { - Ammonia } \\ \text { Absorbent } & \text { - water and sodium hydroxide }\end{array}$

Adding $\mathrm{NaOH}$ to ammonia/water improves the separation of ammonia in the generator and reduces the driving temperature and rectification losses.

Ammonia is highly soluble in water generating $\mathrm{NH}_{4}{ }^{+}$and $\mathrm{OH}^{-}$ ions. Adding sodium hydroxide to the ammonia/water shifts 
the chemical equilibrium towards a more effective separation of ammonia molecules from the generator aqueous solution.

The effect is reducing the bubble point temperature of the ternary mixture.

\section{COEFFICIENT OF PERFORMANCE}

As mentioned the COP of single-stage absorption refrigeration machine COP is defined by the ratio between the refrigerant capacity rate to the rate of heat supplied to the generator and the solution pump performance.

$\operatorname{COP}=\frac{Q_{e}}{Q_{g}}$

The efficiency ratio $(\eta)$ is defined as the ratio of the coefficient of performance to the Carnot coefficient of performance $\left(\boldsymbol{C} \boldsymbol{O} \boldsymbol{P}_{\boldsymbol{c}}\right)$. The Carnot coefficient of performance is the maximum possible coefficient of performance of an ARS under given operating conditions.

$\operatorname{COP}_{c}=\left(\frac{T_{g}-T_{a}}{T_{g}}\right)\left(\frac{T_{e}}{T_{c}-T_{e}}\right)$

$\eta=\frac{C O P}{C O P_{c}}$

\section{CIRCULATION RATIO}

Circulation ratio is defined as the ratio of mass flow rate of solution through the pump to the mass flow rate of the refrigerant through the evaporator, as given by the expression

$f=C . R=\frac{\dot{m}_{s}}{\dot{m}_{r}}$

$f=C \cdot R=\frac{1-w_{w}}{w_{s}-w_{w}}$

\section{MATHEMATICAL MODEL}

For a simplified calculation model of absorption refrigeration machine the following basic conditions are assumed

- There is no pressure drop in the components; the pressure in each component is equal to the vapor pressure of the working solution. The condenser pressure is equal to the generator pressure and the absorber pressure is equal to the evaporator pressure is equal to the evaporator pressure.

- The refrigerant leaving the generator is considered to be in the pure state.

- The solution leaving the absorber is saturated liquid at the temperature and concentration that exists in the absorber.

- The solution leaving the generator is at the same temperature and concentration as in the generator.

- The refrigerant leaves the condenser with the condensation temperature and leaves the evaporator with the evaporating temperature.

- The expansion valves work isenthalpic and heat losses to ambient were assumed to be negligible.

- The condense exit is saturated fluid, the evaporator exit is saturated vapour and the refrigerant leaving the generator exit is superheated vapour.

\section{GENERATOR}

Mass balance

$\dot{\boldsymbol{m}}_{w}-\dot{\boldsymbol{m}}_{r}-\dot{\boldsymbol{m}}_{s}=\mathbf{0}$

Energy balance

$\boldsymbol{Q}_{g}+\left(\dot{\boldsymbol{m}}_{\mathbf{9}} \times \boldsymbol{h}_{\mathbf{9}}\right)-\left(\dot{\boldsymbol{m}}_{\mathbf{1}} \times \boldsymbol{h}_{\mathbf{1}}\right)-\left(\dot{\boldsymbol{m}}_{10} \times \boldsymbol{h}_{10}\right)=\mathbf{0}$

$\dot{m}_{1}=\dot{m}_{r}, \quad \dot{m}_{9}=\dot{m}_{s}, \quad \dot{m}_{10}=\dot{m}_{w}$

$q_{g}=h_{1}-h_{10}+f\left(h_{10}-h_{9}\right)$

\section{CONDENSER}

Mass balance

$\dot{m}_{1}=\dot{m}_{2}$

Energy balance

$\boldsymbol{Q}_{c}+\left(\dot{\boldsymbol{m}}_{\mathbf{2}} \times \boldsymbol{h}_{\mathbf{2}}\right)-\left(\dot{\boldsymbol{m}}_{\mathbf{1}} \times \boldsymbol{h}_{\mathbf{1}}\right)=\mathbf{0}$

$\boldsymbol{q}_{c}=\boldsymbol{h}_{1}-\boldsymbol{h}_{2}$

\section{REFRIGERANT HEAT EXCHANGER}

Mass balance

$\dot{m}_{2}=\dot{m}_{3}, \quad \dot{m}_{5}=\dot{m}_{6}$

Energy balance

$\dot{m}_{2}\left(h_{2}-h_{3}\right)-\dot{m}_{5}\left(h_{6}-h_{5}\right)=0$

$h_{6}=h_{5}\left(1-\varepsilon_{R H X}\right)+\left(\varepsilon_{R H X} \times h_{2}\right)$

$h_{3}=h_{2}-\Sigma_{R H X}\left(h_{2}-h_{5}\right)$

\section{EXPANSION VALVE}

Mass balance

$\dot{m}_{3}=\dot{m}_{4}$

Energy balance

$\dot{m}_{3}\left(h_{3}\right)-\dot{m}_{4}\left(h_{4}\right)=0$

\section{EVAPORATOR}

Mass balance

$\dot{m}_{4}=\dot{m}_{5}$ 
Energy balance

$\boldsymbol{Q}_{e}+\left(\dot{\boldsymbol{m}}_{\mathbf{4}} \times \boldsymbol{h}_{\mathbf{4}}\right)-\left(\dot{\boldsymbol{m}}_{\mathbf{5}} \times \boldsymbol{h}_{\mathbf{5}}\right)=\mathbf{0}$

$\boldsymbol{q}_{e}=\boldsymbol{h}_{5}-\boldsymbol{h}_{4}$

\section{ABSORBER}

Mass balance

$\dot{\boldsymbol{m}}_{s}-\dot{\boldsymbol{m}}_{r}-\dot{\boldsymbol{m}}_{\boldsymbol{w}}=\mathbf{0}$

Energy balance

$\boldsymbol{Q}_{\boldsymbol{a}}+\left(\dot{\boldsymbol{m}}_{\mathbf{7}} \times \boldsymbol{h}_{\mathbf{7}}\right)-\left(\dot{\boldsymbol{m}}_{\mathbf{6}} \times \boldsymbol{h}_{\mathbf{6}}\right)-\left(\dot{\boldsymbol{m}}_{12} \times \boldsymbol{h}_{12}\right)=\mathbf{0}$

$\dot{m}_{7}=\dot{m}_{s}, \quad \dot{m}_{6}=\dot{m}_{r}, \quad \dot{m}_{12}=\dot{m}_{w}$

$q_{a}=h_{6}-h_{11}+f\left(h_{11}-h_{8}\right)$

\section{SOLUTION HEAT EXCHANGER}

Mass balance

$\dot{m}_{8}=\dot{m}_{9}, \quad \dot{m}_{10}=\dot{m}_{11}$

Energy balance

$\dot{m}_{8}\left(h_{9}-h_{8}\right)-\dot{m}_{10}\left(h_{10}-h_{11}\right)=0$

$h_{11}=\left(1-\varepsilon_{S H X}\right) h_{10}-\left(\Sigma_{S H X} \times h_{8}\right)$

$h_{9}=\frac{f}{f+1}\left(h_{10}-h_{11}\right)+h_{8}$

Mass balance

$\dot{m}_{11}=\dot{m}_{12}$

Energy balance

$\dot{m}_{11}\left(h_{11}\right)-\dot{m}_{12}\left(h_{12}\right)=0$

\section{RESULT AND DISCUSSION}

The following figures shows the COP of an absorption refrigeration machine depending upon the generating temperature and evaporating temperature, using ammonia lithium nitrate water mixture. The condensation and absorbing temperature is $24^{\circ} \mathrm{C}, 25^{\circ} \mathrm{C}$. The degree of effectiveness of solution heat exchanger is $75 \%$. As can be seen, the value of COP increase steeply at first when the generator temperature increases and then run more flatly to a final value. It also increases when evaporator temperature increases. If the evaporator temperature varies from -4 to $0^{\circ} \mathrm{C}$, the $\mathrm{COP}$ increases from 0.75 to 0.83 at the generator temperature of $64^{\circ} \mathrm{C}$ as well as from 0.83 to 0.88 at the generator temperature of $80^{\circ} \mathrm{C}$. That means rate of increase in COP is lower at high generator or evaporator temperature.

it can be seen from figures the value of the circulation flow factor decrease with an increasing in the generator and evaporator temperatures.

The variation in thermal load on components depends on generator and evaporator temperature as shown in figure. In this calculation $\mathrm{Te}=0$ to $-4^{\circ} \mathrm{C}, \mathrm{Tc}=24^{\circ} \mathrm{C}, \mathrm{Ta}=25^{\circ} \mathrm{C}, \mathrm{Tg}=64$ to $80^{\circ} \mathrm{C}$, effectiveness of solution heat exchanger is 0.75 are assumed. As it can be seen from figure 5.3, 5.4, when generator temperature increases, the generator and absorber load decreases. If the generator temperature gets higher, the concentration of ammonia leaving the generator is decreases, and hence the circulation ratio decreases, as can be seen from the figure 5.2. More over the weak solution temperature and, hence, the enthalpy is increased by strong solution in the solution heat exchanger. The generator thermal load is decreased both by decreasing the circulation ratio and increasing the enthalpy of strong solution. The enthalpy of superheated ammonia leaving the generator increases with increasing generator temperature.

\section{THE EFFECT OF EVAPORATOR TEMPERATURE}

The coefficient of performance as well as the circulation flow factor depending upon the condensation temperatures. The diagram was represented for different evaporation temperatures -4 to $0^{\circ} \mathrm{C}$ and different condensation temperature 24 to $28^{\circ} \mathrm{C}$. It is clear, that COP decreases as the condensation temperature increases and in addition the circulation factor increases at the same time.

In general, it can be seen from figures, in order to obtain good operating characteristics it is necessary to operate the machine at low value of circulation flow factor. That means the absorption refrigeration machine must operate at high generating and evaporating temperatures as well as at low condensation and absorbing temperatures.

If the evaporator temperature rises, the concentration of strong solution and the circulation ratio decreases. They cause a decrease in the absorber thermal load; on the other hand, decreasing of circulation ratio decreases the generator thermal load.

\section{CONCLUSION}

The theoretical performance analysis of ammonia lithium nitrate water solution and ammonia water sodium hydroxide solution as a working fluid for the absorption refrigeration system for refrigeration temperature -4 to $0^{\circ} \mathrm{C}$ is present in this paper. The preferable working fluid can be consider as a solution with highest COP, lower required generator temperature and circulation ratio low as possible.

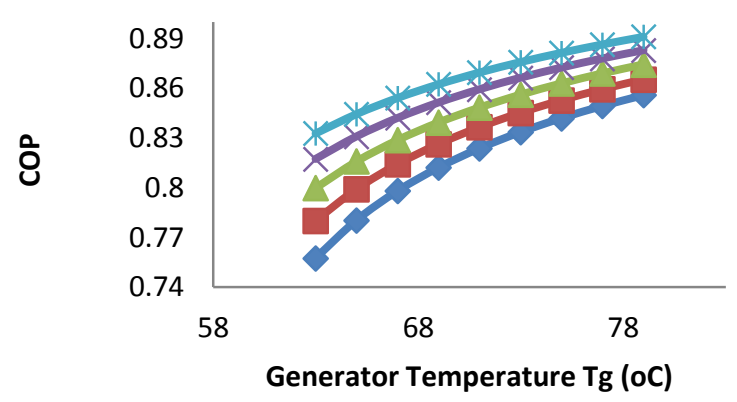




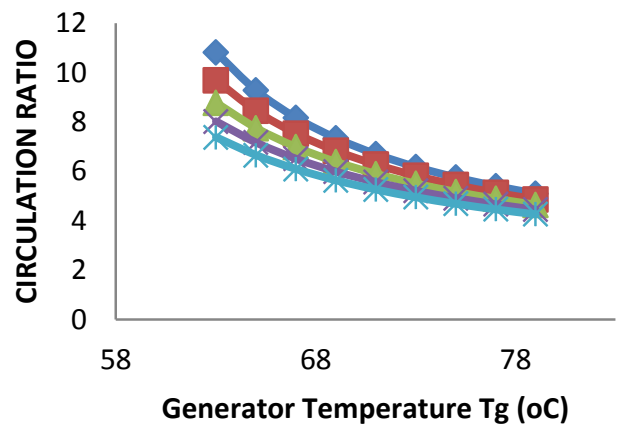

The COP of the system strongly depends on the working condition such as generator, evaporator, absorber and condenser temperature. We observe the range of the COP for the ammonia lithium nitrate water solution system is 0.75 to 0.88 when the generator temperature 64 to $80^{\circ} \mathrm{C}$ and the range of ammonia water sodium hydroxide solution system is 0.35 to 0.78 when the generator temperature 64 to $80^{\circ} \mathrm{C}$.
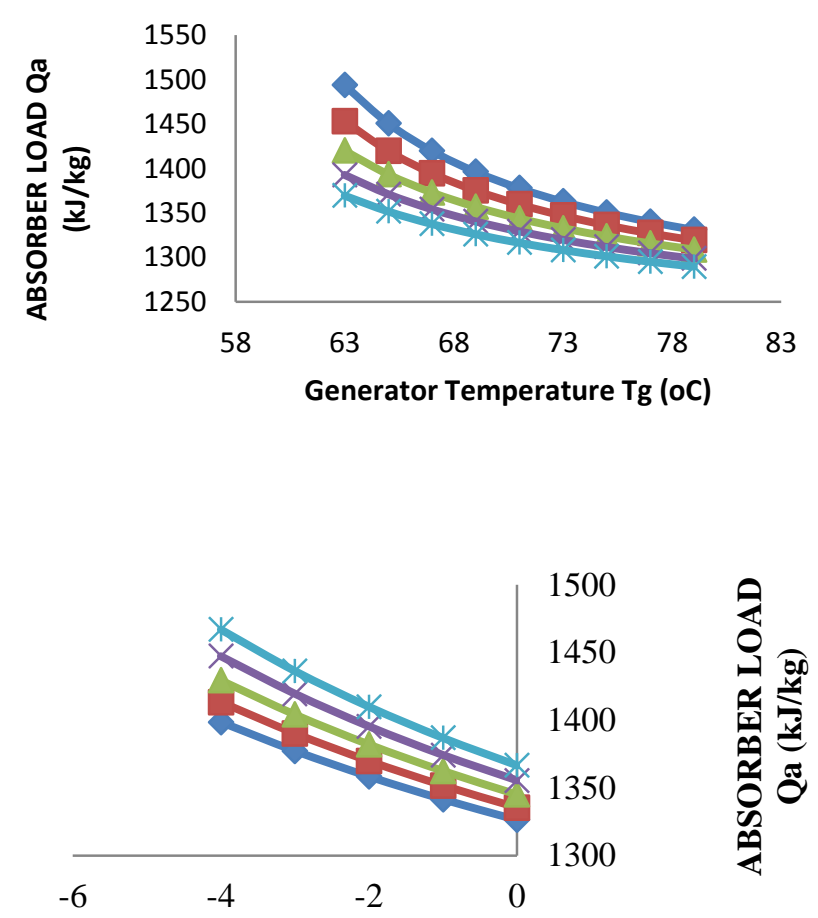

Evaporator Temperature Te (OC)
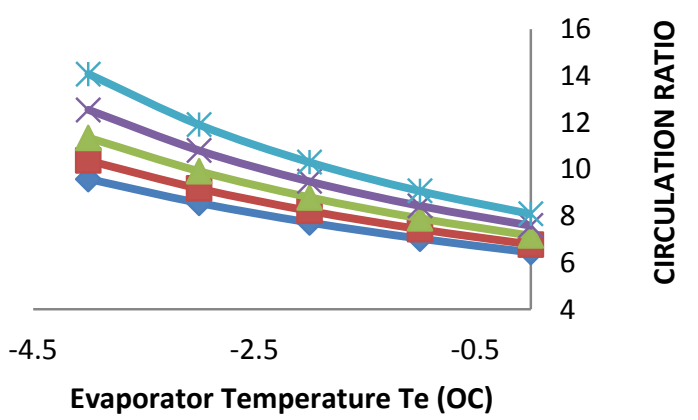

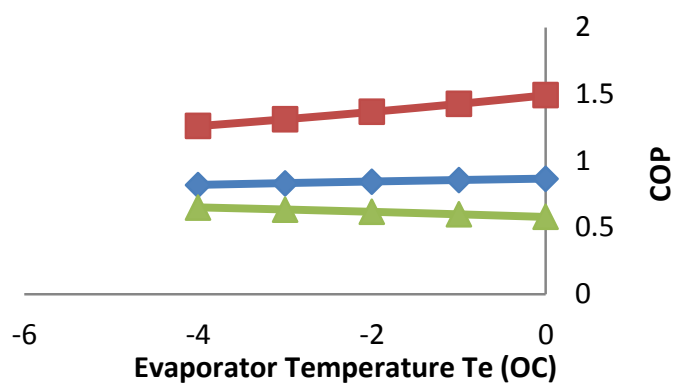

\section{REFERENCE}

[1] Prof. Nilesh B. total. Comparison of the performance of ammonia water and lithium bromide water vapour absorption refrigeration cycle. Int. Journal of Engineering Research and Application ISSN: 22489622.Vol.6.issue 4, April 2016.

[2] Vinay G.Balamuru, Osama M.Ibrahim. Simulation of ternary ammonia-water-salt absorption refrigeration cycles. Int. journal of refrigeration 23 (2000).

[3] A. Bothe. The Mixture ammonia-lithium nitrate/water for the use in absorption cycle (phd.thesis), university Essen Duisburg, germany1989.

[4] W.Revera ,G.Moreno-Quintanar ,C.O. Rivera. Evaluations of a solar intermittent refrigeration system for ice production operated with ammonia lithium nitrate and solution. Solar Energy 85(1)(2011).

[5] Subhadip Roy,M.P.Maya. Analysis of R134a-DMAC Vapour absorption refrigeration system with add-on components. International journal of sustainable Build Environments. (2012); 1.26-35.

[6] S.libten, D.Salavera,M.Valles. Vapour-liquid equilibrium of ammonia+lithiumnitrate+water and ammonia+lithium nitrate solution from $(293$ to 353.15).K.J.chem.Eng.Data 52(3) 2007.

[7] S.libten, D.Salavera,M.Valles.Density, Viscosity and heat capacity of ammonia+lithiumnitrate+water and ammonia+lithium nitrate solution from $(293$ to 353.15).K.J.chem.Eng.Data 53(10) 2008.

[8] B.Babu, G.maruthi Prasad Yadav. Performance analysis of lithium bromide water absorption refrigeration system using waste heat of boiler flue gases.IJERM.ISSO:2349-2058 Volume-02, Issus-02, Feb2015.

[9] Marina Donate. Thermodynamic evaluation of new absorbent mixtures of lithium bromide and organic salts for absorption refrigeration machines. International Journal of Refrigeration 29 (2006); 30-35.

[10] R.J. Romero. Comparison of the theoretical performance of a solar air conditioning system operating with water/lithium bromide and an aqueous ternary hydroxide. Solar Energy Materials \& Solar Cells 63 (2000); 387-399. 
International Journal of Applied Engineering Research ISSN 0973-4562 Volume 15, Number 9 (2020) pp. 911-917

(C) Research India Publications. https://dx.doi.org/10.37622/IJAER/15.9.2020.911-917

[11] Ali karno. Thermodynamic analysis of an absorption refrigeration machine with new working fluid for solar application. Heat Mass Transfer (2008); 45:71-81.

[12] Pitatowsky. Thermodynamic analysis of monomethylamine-water soltion in a single stage solar absorption refrigeration cycle at low generator temperature. Sol energy Mater sol cells (2001); 70:287300.

[13] De Lucas. Performance evaluation and simulation of a new absorbent for an absorption refrigeration system. Int. journal of refrigeration (2004); 27:324-330.

[14] Srikhirin p. A review of absorption refrigeration technologies. Renew sustEnerg Rev (2001); 5:343-72.

[15] Joudi KA. Simulation of simple absorption refrigeration system.Energy Conservation and Management (2001); 42:1575-605. 